\title{
Eficiência dos Dessecantes Paraquat e Diquat na Antecipação da Colmeita do Milho ${ }^{1}$
}

\author{
Effectiveness of the Desiccants Paraquat and Diquat in Anticipating Maize Harvesting
}

MAGALHÃES, P.C. ${ }^{2}$, DURÃES, F.O.M. ${ }^{2}$ e KARAM, D. ${ }^{2}$

\begin{abstract}
RESUMO - O uso de dessecantes na cultura do milho pode trazer benefícios para os agricultores, especialmente visando a disponibilização antecipada do solo para implantação de uma nova cultura, assim como o oferecimento antecipado do produto colhido ao mercado. Dentre os dessecantes disponiveis comercialmente, os herbicidas paraquat e diquat merecem destaque. O objetivo deste trabalho foi avaliar a eficiência dos herbicidas paraquat e diquat, aplicados como dessecantes em diversos estádios de desenvolvimento da cultura de milho, sobre parâmetros produtivos e incidência de doenças nos grãos de milho. O ensaio foi conduzido na Embrapa Milho e Sorgo, Sete Lagoas, MG, utilizando-se os seguintes tratamentos: aplicação de paraquat e diquat aos 14 e 7 dias antes e aos 7 dias depois do ponto de maturação fisiológica (MF), assim como na própria MF. Ambos os produtos foram aplicados na dosagem de $400 \mathrm{~g} \mathrm{ha}^{-1}$. O cultivar de milho utilizado foi o BRS 3101. Aos 0, 3, 6, 9, 12 e 15 dias após a aplicação dos produtos foram coletados 30 grãos de seis espigas aleatórias, para determinação da umidade dos grãos e peso da matéria seca. Na colheita foram avaliados: altura da planta e da espiga, índice de espigas, produção de grãos e espigas e sanidade dos grãos. Os produtos testados não apresentaram diferenças de eficiência para a maioria dos parâmetros avaliados, embora visualmente tenha sido constatado que o paraquat age mais rapidamente do que o diquat na secagem do tecido foliar verde. Apesar disso, quando se detectou alguma diferença entre os dois produtos químicos, o diquat foi superior ao paraquat. Com relação às épocas de aplicação dos produtos, foi constatado que a aplicação dos dessecantes aos 14 dias antes da MF resultou em redução na produção de grãos, devido à diminuição no peso da matéria seca dos grãos, apesar de ter antecipado em dois dias a MF e em quatro dias a colheita. Esse fato ficou mais bem evidenciado com a aplicação do paraquat. A produção de grãos verificada nos tratamentos testemunhas se igualou à dos melhores tratamentos com os dessecantes. O uso do paraquat resultou em grãos com maior porcentagem de infecção por Fusarium subglutinans, patógeno causador dos grãos ardidos em milho. Com relação à época de aplicação dos dessecantes, 14 dias antes da MF foi a que tornou o milho mais suscetível ao ataque desse fungo.
\end{abstract}

Palavras-chave: Zea mays, herbicidas, umidade do grão.

\begin{abstract}
The use of desiccants on maize crop may benefit farmers, especially by anticipating soil availability for the establishment of a new crop, and for the earlier commercialization of the product. The herbicides Paraquat and Diquat are classified as desiccants and are the most prominent in the market. The objective of this work was to evaluate their effectiveness as desiccants applied before corn harvesting. The experiment was carried out at EMBRAPA-Milho e Sorgo, Sete Lagoas, MG, Brazil, by using the following treatments: application of Paraquat and Diquat at 14 and 7 days before and 7 days after physiological maturity (PM) and application at PM. Both products were sprayed at doses of $400 \mathrm{~g} \mathrm{ha}^{-1}$. The cultivar used was BRS 3101 and the parameters were evaluated at 0, 3, 6, 9, 12 and 15 days after application. Thirty maize grains were harvested from 6 ears for evaluation of grain moisture and grain dry matter weight.
\end{abstract}

1 Recebido para publicação em 8/3/2002 e na forma revisada em 9/12/2002.

2 Eng.-Agr. Ph.D., Pesquisadores da Embrapa Milho e Sorgo, Caixa Postal 151, 35700-402 Sete Lagoas-MG, <pcesar@cnpms.embrapa.br>.

Planta Daninha, Viçosa-MG, v.20, n.3, p.449-455, 2002 


\begin{abstract}
At harvesting, the parameters evaluated were: plant and ear height, ear index, grain and ear production and grain sanity. The desiccants evaluated did not cause any differential effects for most characteristics, although visually Paraquat was observed to act more rapidly than Diquat in destroying the green leaf tissue. Statistical differences detected between the two desiccants, revealed that Diquat was more efficient than Paraquat. Application of the desiccants at 14 days prior to PM reduced grain yield due to grain dry matter weight decrease. However, PM was anticipated by two days and harvesting by four days. This was more evident with Paraquat. Grain production obtained with control was similar to that obtained with the best desiccant treatments. The use of Paraquat also resulted in grains with greater incidence of Fusarium subglutinans, which causes "burnt grains" in maize. Desiccant application 14 days before PM made maize most susceptible to this fungus infection.
\end{abstract}

Key words: Zea mays, herbicides, grain moisture.

\section{INTRODUÇÃO}

O uso de dessecantes na cultura do milho pode trazer benefícios para os agricultores, se os objetivos forem disponibilizar o solo mais cedo para uma nova cultura ou o oferecimento antecipado do produto da colheita no mercado. Fatores relacionados ao manejo da cultura em final de ciclo também são importantes e merecem consideração quando se utilizam dessecantes, como: acamamento, quebramento do colmo e infestação tardia de plantas daninhas. Dentre os dessecantes disponiveis no mercado, os herbicidas paraquat (Gramoxone) e diquat (Reglone) merecem destaque. Como esses herbicidas têm ação de contato, com rápida ação dessecante do tecido foliar verde (Summers, 1980; Gubbels \& Kenaschuck, 1981; Nascimento \& Guedes, 1988; Gubbels et al., 1993), a época de aplicação, ou seja, o estádio de desenvolvimento da cultura em que esses produtos são aplicados, torna-se de fundamental importância para evitar perdas no rendimento.

A área foliar do milho é considerada a principal fonte de fotoassimilados para a planta (Magalhães et al., 1995; Magalhães \& Jones, 1990a); segundo Fancelli (1988), perdas nessa fonte poderão se refletir no desenvolvimento da planta e na produção de grãos. Resultados semelhantes com remoção de folhas em milho foram reportados por Jain (1971) e Egharevba et al. (1976), em que se demonstrou que severa perda de folhas até 10 dias após a floração causou queda no rendimento de grãos devido à redução no número de grãos por planta.
Fahl et al. (1994), estudando a maturação de grãos de milho por meio da linha do leite, para aplicação de dessecantes químicos, constataram que aplicações com o dessecante paraquat efetuadas com a linha do leite posicionada no terço superior do grão não alteraram significativamente o decréscimo na umidade que ocorreu durante a maturação nem tampouco a produção de grãos.

A maturação pode ser avaliada por vários métodos, sendo o mais comum a determinação da umidade dos grãos (Fahl et al., 1994). Esse processo, no entanto, requer tempo para a secagem, além da utilização de aparelhagem eletrônica, que nem sempre está disponivel para os agricultores. Outros métodos para se caracterizar a maturidade fisiológica são o de formação da camada preta (Daynard \& Duncan, 1969) ou o de acompanhamento da formação da linha do leite no grão (Afuakwa \& Crookston, 1984). Qualquer que seja o método escolhido, sempre haverá limitações e influências ambientais. Na aplicação de dessecantes é importante caracterizar o estádio de desenvolvimento, para não aplicar o produto cedo ou tarde demais.

Nesse contexto, o objetivo deste trabalho foi avaliar a eficiência do paraquat e do diquat aplicados como dessecantes em diversos estádios de desenvolvimento na cultura do milho.

\section{MATERIAL E MÉTODOS}

O ensaio foi conduzido em área experimental da Embrapa Milho e Sorgo, Sete LagoasMG. O solo utilizado foi um Latossolo Vermelho, 
distrófico, argiloso fase cerrado, preparado de maneira convencional, procedendo-se à adubação, com base na recomendação da análise do solo. Essa recomendação foi de $350 \mathrm{~kg}$ da fórmula $5-20-20+Z n$ por hectare, com $50 \mathrm{~kg}$ de $\mathrm{N} \mathrm{ha}^{-1}$ em cobertura.

Os tratamentos utilizados foram os seguintes:

1. Aplicação de paraquat 14 dias antes da maturação fisiológica (P 14 DAMF).

2. Aplicação de paraquat 7 dias antes da maturação fisiológica (P 7 DAMF).

3. Aplicação de paraquat na maturação fisiológica (P MF).

4. Aplicação de paraquat 7 dias depois da maturação fisiológica (P 7 DDMF).

5. Aplicação de diquat 14 dias antes da maturação fisiológica (D 14 DAMF).

6. Aplicação de diquat 7 dias antes da maturação fisiológica (D 7 DAMF).

7. Aplicação de diquat na maturação fisiológica (D MF).

8. Aplicação de diquat 7 dias depois da maturação fisiológica (D 7 DDMF).

9. Testemunha (sem aplicação).

Ambos os produtos foram aplicados na dosagem de $400 \mathrm{~g} \mathrm{ha}^{-1}$.

As parcelas experimentais foram de seis fileiras de plantio espaçadas de $0,90 \mathrm{~m}$, por $6 \mathrm{~m}$ de comprimento, perfazendo uma área total de $32,4 \mathrm{~m}^{2}$. As duas fileiras laterais foram utilizadas como bordadura externa; as duas centrais, para coleta dos dados de produtividade; e as duas intermediárias, para amostragem de umidade do grão e peso da matéria seca dos grãos.

O delineamento experimental utilizado foi o de blocos ao acaso, num arranjo fatorial $2 \times 4+1$ e quatro repetições.

O cultivar de milho utilizado foi o híbrido triplo BRS 3101. Com relação às características avaliadas, foram feitas coletas de seis espigas de forma aleatória, dentro de cada unidade experimental, objetivando-se determinar a umidade e o peso da matéria seca dos grãos.
Esses parâmetros foram avaliados nas seguintes épocas: 0, 3, 6, 9, 12 e 15 dias após a aplicação dos tratamentos. Já na avaliação do parâmetro peso da matéria seca foram coletados, também de forma aleatória, 30 grãos da metade das espigas de cada unidade experimental. Durante a colheita também foram avaliados os seguintes parâmetros: altura da planta, altura da inserção da espiga, índice de espigas, produção de grãos, produção de espigas e sanidade de grãos.

Cada parcela experimental foi distanciada de $2 \mathrm{~m}$ uma da outra, a fim de facilitar a operação de aplicação dos produtos, assim como evitar o efeito de deriva. Entre blocos a distância foi de $4 \mathrm{~m}$. A pulverização dos produtos foi realizada em área total, manualmente, utilizando-se um pulverizador costal equipado com barra de oito bicos APJ-110.R e pressão de $2,75 \mathrm{kgf} \mathrm{cm}^{-2}$. A pressão de pulverização foi obtida por meio de um cilindro de $\mathrm{CO}_{2}$ e controlada por um manômetro de baixa pressão.

A umidade dos grãos foi determinada pelo Laboratório de Análise de Sementes da Embrapa Milho e Sorgo, pelo método Umidade em Estufa (Brasil, 1992). A análise de sanidade dos grãos foi feita pelo Laboratório de Patologia de Sementes e Grãos da Embrapa Milho e Sorgo, através do método do papel-filtro com congelamento (Limonard, 1966).

A determinação dos estádios de desenvolvimento dos grãos, assim como da maturação fisiológica e, por conseguinte, da época de aplicação dos produtos, foi feita através de amostragens periódicas, utilizando-se as seguintes características: umidade dos grãos, formação da camada preta e acompanhamento da linha do leite.

Os dados obtidos foram submetidos à análise de variância e as médias comparadas pelo teste de Duncan a 5\% de probabilidade. Foi realizada também análise de regressão, procurando-se selecionar um modelo matemático que melhor expressasse a relação entre os dias após a aplicação dos produtos e as variáveis umidade de grãos e peso da matéria seca de grãos.

\section{RESULTADOS E DISCUSSÃO}

Após a aplicação dos dessecantes, a análise de variância não detectou diferenças 
estatísticas significativas entre os tratamentos no que se refere ao parâmetro umidade de grãos. Resultado semelhante foi encontrado por Fahl (1994), cujas aplicações aconteceram quando a umidade dos grãos se encontrava em $42 \%$, o que corresponde, no presente trabalho, a 14 DAMF. Entretanto, a interação entre estádios de desenvolvimento dos grãos e os períodos de avaliações foi altamente significativa, sendo, assim, calculadas equações de regressão para cada estádio nas diversas avaliações (Figura 1). Observa-se que a redução do parâmetro umidade dos grãos, quando os produtos foram aplicados aos 14 DAMF, foi superior em relação às demais épocas. Paraquat e diquat aplicados na MF e aos 7 DDMF apresentaram semelhanças na redução da umidade dos grãos. Nota-se, na mesma figura, que a aplicação dos produtos dessecantes aos 14 DAMF antecipou em apenas dois dias o nível da umidade dos grãos verificado na maturação fisiológica, ao passo que na aplicação aos 7 DAMF não se observou antecipação nos níveis de umidade dos grãos na MF (Figura 1). Deve ser ressaltado que a umidade dos grãos na MF ficou em torno de $29 \%$.

O peso da matéria seca dos grãos amostrados na MF atingiu em torno de 8 g (Figura 2), sendo influenciado apenas pela interação entre estádios de desenvolvimento e dias após a aplicação dos produtos. O teste de regressão foi significativo para as avaliações realizadas aos

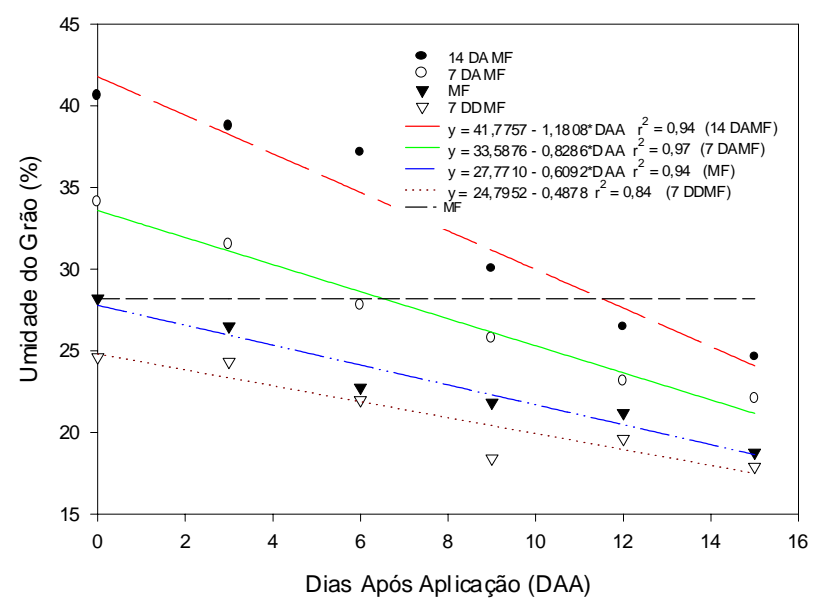

Figura 1 - Equações de regressão da umidade do grão em função do período após a aplicação de paraquat e diquat (média dos dois produtos). Embrapa Milho e Sorgo, Sete Lagoas-MG, 2001.
14 e 7 DAMF. Observa-se, através da Figura 2, que a aplicação do produto aos 14 DAMF diminuiu o peso da matéria seca dos grãos em cerca de $12,5 \%$, enquanto aos 7 DAMF o decréscimo foi de 4\%; portanto, com valor inferior quando comparado ao peso da matéria seca dos grãos na MF. Assim, a antecipação de dois dias para se atingir a umidade dos grãos na $\mathrm{MF}$, com a aplicação dos produtos aos 14 DAMF, mostrou não ser vantajosa, uma vez que este tratamento provocou redução na matéria seca dos grãos, conforme observado nas Figuras 1 e 2. Ressalta-se que, apesar de os tratamentos $14 \mathrm{e}$ 7 DAMF diminuírem o peso da matéria seca dos grãos, estes continuaram a acumular massa seca, porém em taxas menores (Figura 2). Esse fato, provavelmente, se deveu à remobilização dos fotoassimilados armazenados nos colmos para os grãos, uma vez que as folhas se encontram secas e, portanto, deixam de atuar como fonte (Magalhães \& Jones 1990b; Magalhães et al., 1998, 2000). Trabalhos realizados com milho com aplicação involuntária de herbicidas (Magalhães et al., 2000) e com deriva simulada de dessecantes (Magalhães et al., 2001) revelaram que, apesar dos danos verificados na parte aérea, diminuindo assim a fonte de assimilados, a planta foi capaz de produzir mais do que a testemunha, devido principalmente à translocação de metabólitos do colmo em direção à espiga.

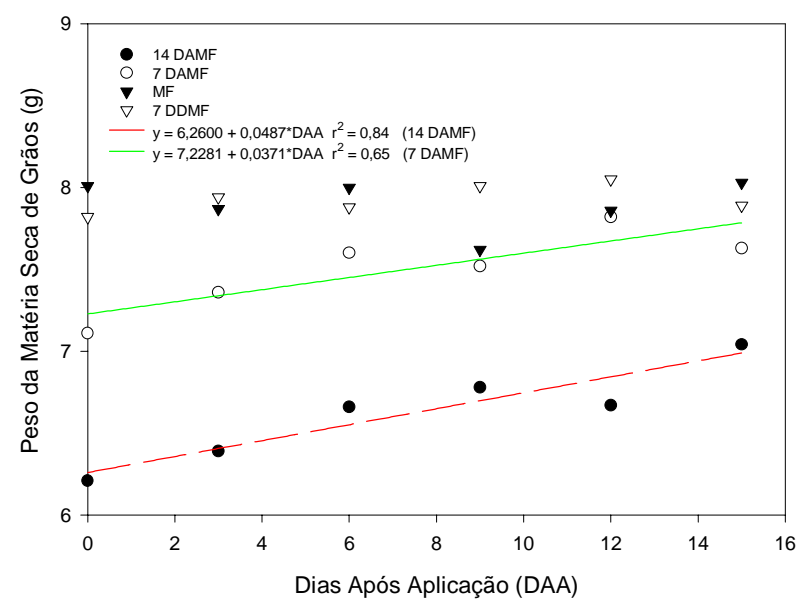

Figura 2 - Equações de regressão do peso seco de grãos em função do período após a aplicação de paraquat e diquat (média dos dois produtos). Embrapa Milho e Sorgo, Sete Lagoas-MG. 2001. 
Para a característica peso de grãos, foram detectados diferenças entre os produtos e os estádios de aplicação (Figura 3). O dessecante paraquat aplicado aos 14 DAMF proporcionou redução na produção de grãos. A aplicação dos herbicidas diquat e paraquat nas avaliações realizadas aos 7 DAMF e 7 DDMF não afetou a produção de grãos de milho, não diferindo, portanto, da testemunha sem aplicação de dessecante (Figura 3). A produção de espigas (Figura 4), como era de se esperar, mostrou resultados similares aos da produção de grãos, em que os melhores tratamentos, com aplicação dos dessecantes, foram semelhantes estatisticamente à testemunha. Fahl et al. (1994) não verificaram efeito do dessecante paraquat aplicado a partir de 127 dias após o plantio. Esse resultado tem como hipótese o fato de que nessa época não havia mais acúmulo de matéria seca nos grãos, ou seja, o ponto de maturação fisiológica já tinha sido atingido. No presente trabalho, aplicações com o mesmo dessecante diminuíram a produção aos 14 DAMF, pois nesta época a planta demanda muito da fonte de fotoassimilados e muitas vezes somente o colmo não consegue suprir as necessidades da planta de milho (Magalhães et al., 1998).

Na Figura 5 observam-se os resultados relacionados ao aspecto sanitário dos grãos.

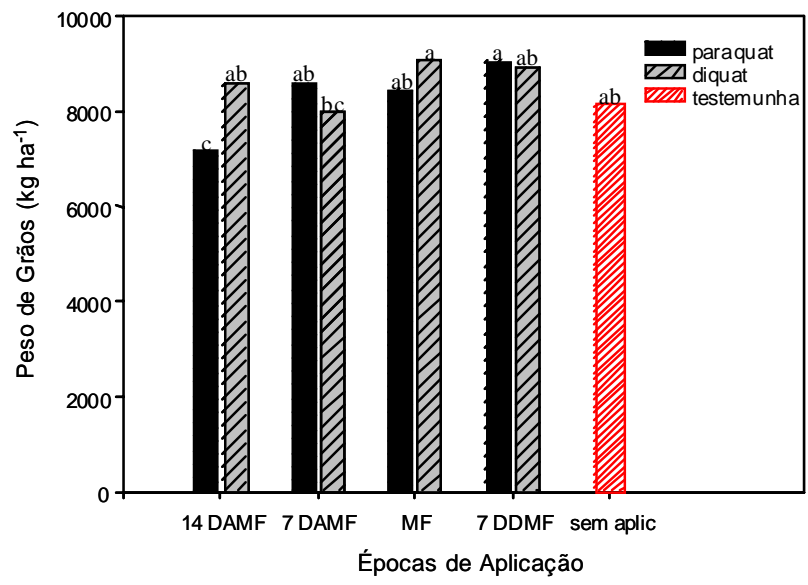

Médias nas colunas seguidas pela mesma letra não diferem entre si a 5\% de probabilidade pelo teste de Duncan.

Figura 3 - Massa de grãos obtida aos 7 e 14 dias antes, aos 7 dias após e na maturação fisiológica, após aplicação de paraquat e diquat. Embrapa Milho e Sorgo, Sete LagoasMG. 2001.
As parcelas dessecadas com paraquat apresentaram maior contaminação com Fusarium subglutinans, em comparação com o dessecamento por diquat e a testemunha. O período de aplicação dos tratamentos com maior contaminação foi aos 14 DAMF (Figura 5). Este fungo está associado aos sintomas denominados grãos ardidos, sendo comum sua ocorrência nas diversas regiões brasileiras, exceto os estados do sul do Brasil, onde prevalece o Fusarium graminearum. Na Região Sudeste, $F$. subglutinans tem sido considerado o principal causador de grãos ardidos em milho (Pinto, 2000). Resultados de pesquisa desenvolvida pelo mesmo autor mostram que os fungos toxígenos, durante a colonização dos grãos na fase de pré-colheita, biossintetizam micotoxinas chamadas micotoxicoses, as quais são consideradas altamente nocivas à saúde animal e humana. A dieta de suínos, bovinos e aves composta de grãos de milho com elevado nível de micotoxinas significa, ao mesmo tempo, risco e prejuízos. As micotoxinas causam danos irreversiveis à saúde dos animais e, adicionalmente, comprometem a sanidade de quem consome carne, leite e produtos derivados dos animais intoxicados.

Na Figura 6 é apresentada a umidade dos grãos em três amostragens realizadas próximo à colheita final. Em 10/11/2000, os grãos

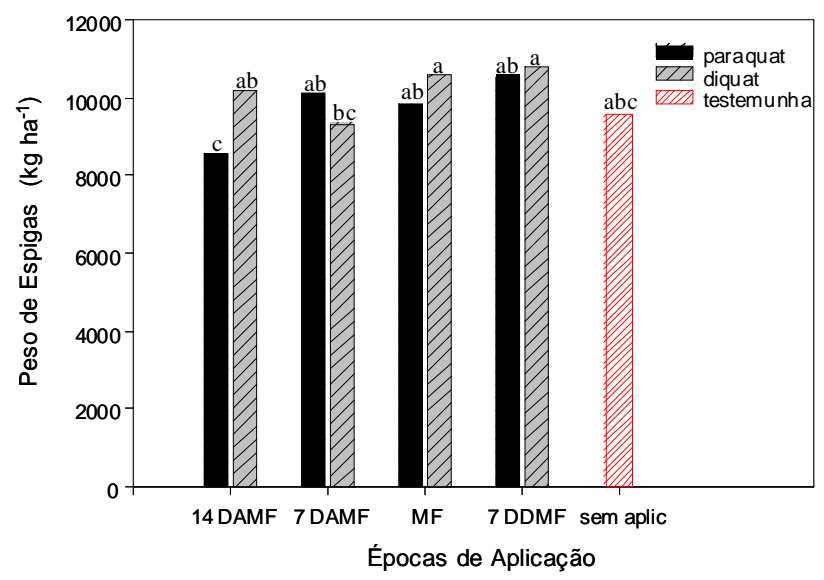

Médias nas colunas seguidas pela mesma letra não diferem entre si a 5\% de probabilidade pelo teste de Duncan.

Figura 4 - Massa de espigas obtida aos 7 e 14 dias antes, aos 7 dias após e na maturação fisiológica, após aplicação de paraquat e diquat. Embrapa Milho e Sorgo, Sete LagoasMG. 2001. 
provenientes dos tratamentos apresentaram teor médio próximo de $19 \%$ de umidade, e os tratamentos referentes à aplicação durante os 14 DAMF evidenciaram teor de umidade próximo de 16,5\%. Em 17/11/2000 ocorreu a colheita nos tratamentos P 14 DMF e D 14 DAMF, quando estes apresentavam teor de umidade de $16 \%$. A colheita para os demais tratamentos

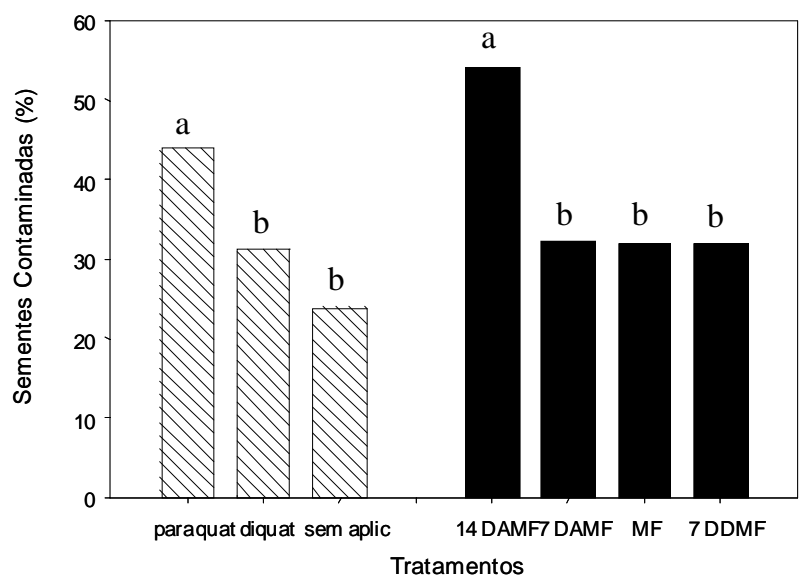

Figura 5 - Porcentagem de sementes contaminadas por Fusarium subglutinans obtida aos 7 e 14 dias antes, aos 7 dias após e na maturação fisiológica, após aplicação de paraquat e diquat. Embrapa Milho e Sorgo, Sete LagoasMG. 2001.

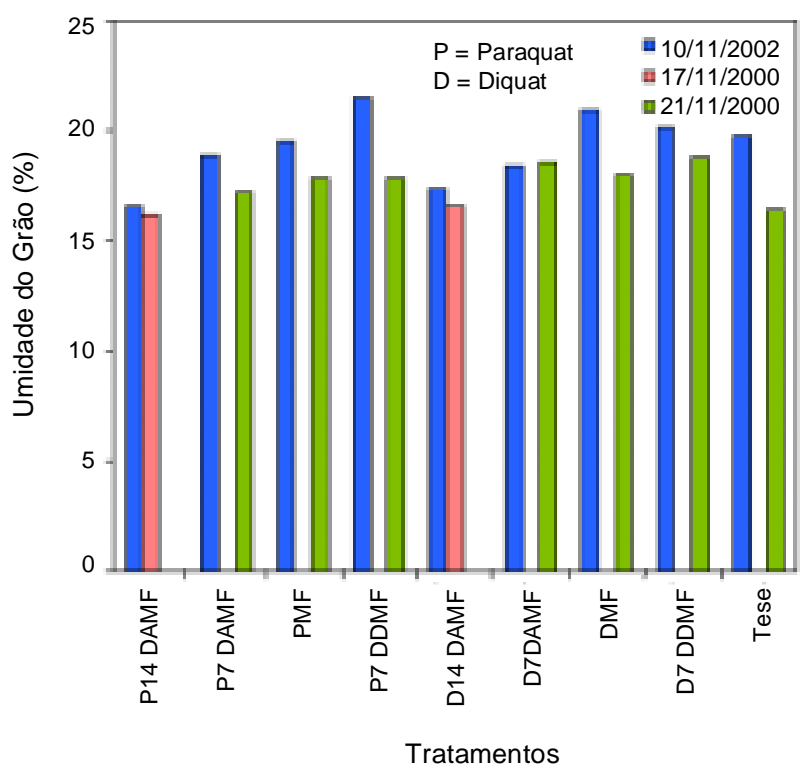

Figura 6 - Umidade dos grãos observada nos diversos tratamentos em três datas de amostragem. Embrapa Milho e Sorgo, Sete Lagoas-MG, 2001. ocorreu quatro dias depois, com umidade dos grãos em $17 \%$. Assim, pode-se concluir que a antecipação de colheita nos tratamentos com 14 DAMF, em relação aos demais, foi de quatro dias.

Na Tabela 1 são apresentadas as características altura final da planta, altura de espiga e índice de espiga, para as quais não foram detectadas diferenças estatisticamente significativas.

Tabela 1 - Médias de altura da planta, altura da espiga e índice de espiga nos diversos tratamentos testados. Embrapa Milho e Sorgo, Sete Lagoas-MG. 2001

\begin{tabular}{|c|c|c|c|}
\hline \multirow[b]{2}{*}{ Tratamento } & \multicolumn{2}{|c|}{ Características } & \multirow[b]{2}{*}{$\begin{array}{c}\text { Índice de } \\
\text { espiga }\end{array}$} \\
\hline & $\begin{array}{l}\text { Altura da } \\
\text { planta } \\
(\mathrm{m})\end{array}$ & $\begin{array}{l}\text { Altura de } \\
\text { espiga } \\
(\mathrm{m})\end{array}$ & \\
\hline Paraquat 14 DAMF & 2,10 & 1,18 & 1,29 \\
\hline Paraquat 7 DAMF & 2,00 & 1,13 & 1,49 \\
\hline Paraquat MF & 2,03 & 1,19 & 1,33 \\
\hline Paraquat 7 DDMF & 2,05 & 1,15 & 1,41 \\
\hline Diquat 14 DAMF & 2,16 & 1,23 & 1,48 \\
\hline Diquat 7 DAMF & 2,06 & 1,15 & 1,37 \\
\hline Diquat MF & 2,08 & 1,18 & 1,44 \\
\hline Diquat 7 DDMF & 2,04 & 1,14 & 1,32 \\
\hline Testemunha & 2,05 & 1,11 & 1,45 \\
\hline Valor de F & 1,003 n.s. & 0,642 n.s. & 2,047 n.s. \\
\hline CV (\%) & 4,57 & 7,46 & 7,34 \\
\hline
\end{tabular}

Neste trabalho foi constatado que o tratamento aos 14 DAMF, apesar de ter antecipado em dois dias a maturação fisiológica e em quatro dias a colheita, provocou diminuição no peso da matéria seca dos grãos e, por conseguinte, na produção de grãos. Esse fato ficou mais bem evidenciado com a aplicação do paraquat. $\mathrm{O}$ uso do paraquat também resultou em grãos com maior porcentagem de infecção por Fusarium subglutinans, causador dos grãos ardidos em milho.

\section{LITERATURA CITADA}

AFUAKWA, J. J.; CROOKSTON, R. K. Using the kernel milk line to visually monitor grain maturity in maize. Crop Sci., v. 24, p. 687-691, 1984.

BRASIL. Ministério da Agricultura e Reforma Agrária. Secretaria Nacional de Defesa Agropecuária. Regras para análise de sementes. Brasília, DF: 1992. 365 p. 
DAYNARD, T. B.; DUNCAN, W. G. The black layer and grain maturity in corn. Crop Sci., v. 9, p. 473-476, 1969.

EGHAREVBA, P. N.; HARROCKS, R. D.; ZUBER, M. S. Dry matter accumulation in maize response to defoliation. Agron. J., v. 68, p. 43-49, 1976.

FAHL, J. I. et al. Avaliação da maturação de grãos de milho através da linha do leite para aplicação de dessecantes químicos. Bragantia, v. 53, n. 2, p. 209-218, 1994.

FANCELLI, L.A. Influência do desfolhamento no desempenho de plantas e de sementes de milho (Zea mays L.). Piracicaba: ESALQ, 1988. 172 p. Tese (Doutorado em Solos e Nutrição de Plantas) - Escola Superior de Agricultura "Luiz de Queiroz", 1988.

GUBBELS, G. H.; KENASCHUK, E. O. Desiccation of flax with diquat. Can. J. Plant Sci., v. 61, p. 575-581, 1981.

GUBBELS, G. H.; BONNER, D. M.; KENASCHUK, E. O. Effect of time of swathing and desiccation on plant drying, seed color and germination of flax. Can. J. Plant Sci., v. 73, p. 1001-1007, 1993.

JAIN, T. C. Contribution of stem, lamina and ears to the drymatter production of maize (Zea mays L.) after ear emergence. Ind. J. Agric. Sci., v. 41, p. 579-583, 1971.

LIMONARD, T. A modified blotter test for seed health. Nether. J. Plant Pathol., v. 72, p. 319-321, 1966.

MAGALHÃES, P. C.; JONES, R. Aumento de fotoassimilados sobre os teores de carboidratos e nitrogênio em milho. Pesq. Agropec. Bras., v. 25, n. 12, p.1755-1761, 1990a.
MAGALHÃES, P. C.; JONES, R. Aumento de fotoassimilados na taxa de crescimento e peso final dos grãos de milho. Pesq. Agropec. Bras., v. 25, n. 12, p. 1747-1754, 1990b.

MAGALHÃES, P. C.; DURÃES, F. O. M.; PAIVA, E. Fisiologia da planta de milho. Sete Lagoas: EMBRAPACNPMS, 1995. 27 p. (EMBRAPA-CNPMS. Circular Técnica, 20).

MAGALHÃES, P. C.; DURÃES, F. O. M.; OLIVEIRA, A. C. Efeitos do quebramento do colmo no rendimento de grãos de milho. Ci. Agrotecnol., v. 22, n. 3, p. 279-289, 1998.

MAGAlHÃES, P. C.; SILVA, J. B.; DURÃES, F. O. M. Fitotoxidade de herbicidas aplicados em pós emergência na fase inicial da cultura do milho. Planta Daninha, v. 18, n. 2, p. 277-284, 2000.

MAGALHÃES, P. C. et al. Efeito de doses reduzidas de glyphosate e paraquat simulando deriva na cultura do milho. Planta Daninha, Viçosa, v. 19, n. 2, p. 247-253, 2001.

NASCIMENTO, W. M.; GUEDES, A. C. Efeito do paraquat na qualidade da semente de cenoura. Horticult. Bras., v. 6, n. 1, p.38, 1988.

PINTO, N. F. J. A. Incidência de grãos ardidos em cultivares de milho precoce. Sete Lagoas: EMBRAPA Milho e Sorgo, 2000. 3 p. (EMBRAPA Milho e Sorgo. Comunicado Técnico, 24).

SUMMERS, L. A. The Bipyridinium herbicides. New York: Academic Press, 1980. 449 p. 